\title{
BETWIXT AND BETWEEN: LIMINALITY AND DISSONANCE IN DEVELOPING THRESHOLD COMPETENCES FOR RESEARCH SUPERVISION IN SOUTH AFRICA
}

\author{
S. M. Maistry \\ School of Education \\ University of KwaZulu-Natal \\ Durban, South Africa \\ e-mail: maistrys@ukzn.ac.za
}

\section{ABSTRACT}

Neoliberal performativity imperatives that drive the strategic vision and mission of many higher education institutions in South Africa have begun to shape the higher education project in particular ways. While research and knowledge production will always remain the defining hallmark of a university, the fragility of the system to deliver on this objective in substantive ways remains a challenge. Graduate supervision capacity and competence continues to be a serious obstacle for many higher education institutions in South Africa. Of concern for this article, is that in the quest to rapidly develop supervision competence amongst faculty, to what extent will fast tracking be at the expense of learning as 'process' and deep conceptual development of the young academic. How do novice supervisors negotiate liminality as they learn to be researchers while simultaneously teaching the craft to their assigned research students? In this article, I reflect on my experiences of teaching a structured, accredited postgraduate supervision programme at seven merged higher education institutions in SA from 2014 to2016. I argue that high-level research supervision depends on having certain minimum threshold research supervision competences, the achievement of which necessitates a process approach. Young novice faculty however, have to negotiate a precarious liminal space in which they learn the research 'trade/craft' as apprentice whilst simultaneously teaching the research 'trade/craft' to research candidates they supervise. I engage the implications of this risky and contradictory agenda for novice faculty and a discussion of how this 'parallel learning', which entails learning the research craft and simultaneously learning how to teach the research craft is likely to play out in the South African higher education research context.

Keywords: research supervision; liminality; supervision as pedagogy

\section{INTRODUCTION}

Victor Turner, in his extrapolation of the thesis of ritual in society by renowned $19^{\text {th }}$ century French anthropologist Arnold van Gennep (1873-1957), coined the phrase 'betwixt and between' in his analysis of the rites of passage that prevail in sociocultural systems (Turner 1974). He theorized the construct 'liminality' which refers to a state of 'inbetweeness' or 
ambiguous transitional space in which identity conflict and aspirational identity formation occurs (see below for further explication). His work has since been applied in a range of contexts and disciplines including Sociology, Drama and Organisational Studies and Teacher Education (Cook-Sather 2006). In this article I examine the how novice supervisors negotiate the 'rite of passage' as they transition from research student to supervising student research. This is a particularly germane issue as a successful postgraduate sector in South Africa hinges on the competence of faculty that have to give effect to the national postgraduate research project. In a provocative piece entitled 'Are doctoral studies in South African higher education being put at risk?' Waghid cautions about the potential risk that presents, namely, that a narrow, technicist approach to doctoral studies has started to gain currency in South African higher education. He argues in particular, that the country's peculiar historical educational context has created an 'epistemological threat' that necessarily requires due consideration and that the problem is likely to be compounded when 'novice' supervisors are required to promote advanced doctoral work (Waghid 2015).

My intention is to contribute to the debates which highlight the tensions in the South African post graduate sector. These have been well documented in recent published works (See Waghid 2005; Teferra 2015; Thaver and Holtman 2015). These polemical pieces flag the multiple pieces of a complex puzzle as it relates to doctoral research in South African. One specific puzzle piece which this article will focus on is the teaching and learning of the research supervision craft. In particular, I hope to initiate contemplation and theorization on what might constitute threshold competences for research supervisors of advanced research degrees (masters and doctorates). While a plethora of research on teaching in South Africa (both school and higher education) abounds, there is a dearth of scholarship on research supervision or the 'teaching' (and learning) of research supervision. There is however a growing body of international scholarship on supervisory practices and in recent years, there has been the emergence of a body of post-liberal scholarship that argues for the reconceptualization of research supervision from the traditional liberal (technicist) approach towards conceptualizing research supervision as pedagogy, that which may seek 'to problematise language, subjectivity, power and identity in ways that emphasise the fragmented, partial and multiple nature of the self' (Manathunga 2009, 344); a refocusing of supervision on the development of the PhD candidate with high-level conceptual skills as opposed to a preoccupation with the delivery of hard-bound ultimate paper product (the thesis report).

The extent to which this potentially progressive move has infused the South African higher education research supervision culture remains a moot question. There is however a distinct 
sense that the pressure to acquiesce has seen higher education institutions increasingly shape their policies to conform with a neoliberal agenda, centred on competitive participation in the knowledge economy (Adkins 2007). While the notion of postgraduate supervision as pedagogy (Clegg 2014) has gained currency internationally in recent years, evolving scholarship in this field has begun to indicate a need for more nuanced approaches to supervision that go beyond the traditional Oxford model (Wisker, Robinson and Schacham 2007; Burford 2014; Grant 2014).

In South Africa, recent developments and pronouncements emanating from the National Policy Commission (2012) through the National Development Plan indicate a strongly neoliberal knowledge-economy agenda for higher education in South Africa. Exaggerated and somewhat unrealistic targets have been set for $\mathrm{PhD}$ production. This can be seen in the projected target outputs for $\mathrm{PhDs}$, envisaged to increase from the current 1500 per annum to 5000 per annum by 2030 (National Planning Commission 2012). While the ASSAF report also signals the importance of strengthening the PhD profile of the country, it highlights institutional factors that need consideration if this agenda is to be fulfilled (ASSAF 2010). An issue of particular concern is that the entities which are expected to deliver on this, namely the higher education academic fraternity in South Africa, is severely under-capacitated in regard to PhD-qualified personnel.

I draw on the insights offered by Meyer and Land who argue that in order to access the tenets of a discipline, it is necessary for a person to master key concepts that may be central to the discipline. They coined these 'threshold concepts' that necessarily lay the foundational principles that facilitate epistemic access to the discourses and practices of a discipline (Land, Meyer, and Bailie 2010). Drawing on this framework, Wisker, in her ongoing advancement of scholarship on research supervision, argues for the development of a tentative set of threshold competences that PhD students should master; a prerequisite conceptual knowledge and skill set that may scaffold success in a PhD programme (Wisker 2012). In this article I hope to extend the principle of developing threshold competence to the 'teaching of research' (research supervision). In other words, how might we move novice supervisors towards the development of threshold competences for effective research supervision in a rapidly changing higher education market?

In a highly competitive market for $\mathrm{PhD}$ graduates, South African universities struggle to compete with the private sector and the state to attract and retain high calibre $\mathrm{PhD}$ graduates. The Council of the Academy of Science of South Africa (ASSAF) in their report on the status of the South African $\mathrm{PhD}$ reflected on the multiple challenges facing higher education 
institutions in SA. Amongst the key recommendations, was the need to 'Target specific institutions with existing capacity and established track records for scaling up the production of PhDs ...' (ASSAF 2010). As was to be expected, the above recommendation has been largely ignored as it was perceived as an exclusionary tactic that was not likely to find favour with higher education institutions that lacked these credentials. Moreover, the national ministry also lacked any significant muscle or political will to give effect to this recommendation. If anything higher education institutions across the country have been encouraged to develop their capacities to produce more $\mathrm{PhD}$ graduates and to increase the percentage of $\mathrm{PhD}$ qualified faculty. Given the diversity of higher education institutions in terms of their ability to deliver on this agenda, one can expect that this project was likely to play out differently across institutions. $\mathrm{A} \mathrm{PhD}$ as minimum qualification for teaching at university level in South Africa has rapidly gained momentum in the last decade. Clearly, HEIs in South Africa do not have the luxury of enforcing this kind of regime given the huge chasm in the $\mathrm{PhD}$ labour market, but this 'progressive' 'new' benchmark coupled with a surveillance of individual research productivity has impacted the higher education system in particular ways, an issue this article takes up.

The South African higher education system remains a highly differentiated system, (although some would argue that it is not), comprising 'newly' merged institution, the sacrosanct, unencumbered institutions, universities of technology, and comprehensive universities. Each of these has embraced the PhD project with different levels of intensity and vigor. While one would expect that the top research institutions might well have a critical mass of existing research supervision competence to advance the local $\mathrm{PhD}$ project, this might not always be an accurate assumption, as the data indicates that high research productivity, particularly in the hard sciences tends to obfuscate under-productivity in other fields at these institutions. Professional disciplines like Accounting and Law for instance are to a fair extent inhabited by professoriate without $\mathrm{PhD}$ qualifications and in some instances with somewhat thin research productivity profiles. $\mathrm{PhD}$ accountants and attorneys are rare and seldom ply their trade in academia. There is growing pressure to register for $\mathrm{PhD}$ study and to supervise postgraduate research in these fields, a predicament facing especially late career academics in these fields. The point then is that while it may appear that research supervision capacity is an affliction of historically disadvantaged institutions, even research-led institutions have $\mathrm{PhD}$ supervision capacity challenges.

The ASSAF report also cautioned about the massification and proliferation of $\mathrm{PhD}$ programmes (given the remunerative potential that $\mathrm{PhD}$ graduation presents) especially at institutions with limited existing capacity. The report reflected a concern about diminished 
quality arguing for strengthening the quality of the $\mathrm{PhD}$. Again, while the intent of the recommendation is noble, it can be argued that the strong (institutions) are likely to become stronger (both financially and in terms of experience and capacity development) at the expense of their 'lesser' counterparts. Despite the recommendations of the ASSAF Report higher education institutions across the board have forged ahead with new $\mathrm{PhD}$ programmes for the general public while simultaneously developing various strategies to bring existing faculty up to $\mathrm{PhD}$ level, and attempting to build the supervision competences of such colleagues. $\mathrm{PhD}$ graduate production initiatives are thus underway in South African education. In a sector struggling with a multitude of challenges around transformation, (including racial transformation), the 'new' young academic is confronted with the schizophrenic demands of the institutions in which they work, as they struggle to come to terms with the 'fast tracking' that they are they have to endure, namely achieving the $\mathrm{PhD}$ and simultaneously mastering the research supervision craft.

While some institutions have capacity and well established (even accredited) research supervision courses which they are able to lever in an attempt to address the $\mathrm{PhD}$ and research supervision project, many institutions in South Africa draw on external consultancies as well as supervision programmes offered at fellow HEIs to fulfill this need. One such programme (entitled Strengthening Postgraduate Supervision) is on offer via CHERTL (Centre for Higher Education, Teaching and Research) at Rhodes University. This programme was developed collaboratively by a team of experienced research supervisors at Nuffic (Netherlands organization for international co-operation in higher education) and eight South African tertiary institutions (Rhodes University, University of Fort Hare, University of Cape Town, Stellenbosch University and the University of Venda). The course, equivalent to $30 \mathrm{NQF}$ credits and pitched at NQF level 8 was structured in three phases. Phase one entailed three-days of face-to-face interactive contact sessions (8 hours per day) run by two facilitators (main and cofacilitator). This was followed by a six to eight week structured interactive online work programme. The final phase was a further three-day interactive face-to-face session. Phases two and three were conducted by one of the main facilitator. As an accredited course, it had four distinct outcomes that participants had to demonstrate competence in, namely to:

- $\quad$ Be aware of power relations in supervision and the necessity of creating inclusive learning environments

- $\quad$ Be able to provide a learning environment that emphasizes the importance of scholarship

- $\quad$ Be able to use supervisory practices that enhance student development 
- $\quad$ Be able to manage supervisory processes

Each of these outcomes had a set of assessment criteria that signaled the specific competencies that were being targeted by the programme. The course was assessed at the level of a Postgraduate Diploma and was subject to the Rhodes University's moderation protocol. Course facilitators were drawn from a pool of active researchers who had to have had a record of successful PhD supervision. For the record, I had no involvement in the development of the programme (nor its materials) but was approached in 2014 by CHERTL to be a facilitator. I have since facilitated all three phases of the programme at Walter Sisulu University (twice), University of Venda, University of the North West, Nelson Mandela Metropolitan University, and University of the Western Cape and the University of Limpopo.

At the outset I want to state categorically that the intention of this article is certainly not to glorify the programme or romanticize its achievements. If anything my view is that the programme's impact is only likely to manifest in the long term and may be marginal at best. I will however attempt to trouble the implicit assumptions that such programmes work from, with a view to illuminating and better understanding the dissonance experienced and articulated by participants in the programme as they negotiate the liminal spaces they occupy as they learn to become research supervisors.

\section{ENGAGING ‘LIMINALITY’ AND THRESHOLD CONCEPTS - AS ILLUMINATING CONCEPT}

In a seminal piece entitled Rites de Passage French anthropologist Arnold van Gennep theorised the significance of rituals as individuals transition through their lives - from birth to puberty, to marriage and ultimately death. Rite of passage as a social construct has since become key in anthropological literature and was given due prominence by Victor Turner who devoted his attention to an analysis of the marginal or liminal stage in his highly acclaimed piece Betwixt and Between: The Liminal Period in Rites de Passage (1964). Liminality is a concept derived from the Latin word limen (threshold); the concept is indicative of a period of uncertain transition as a person moves between 'ascribed statuses (Turner 1974). It is considered a process of temporarily removing limits - a phase in which a person is likely to experience anxiety and conflict and depleted self-esteem as they come to terms with the new competences they are expected to master (Szakolczai 2009). Individuals in the state of liminality endure a painful separation from their existing identity; as they negotiate this rite of passage, they are likely to show obedience and humility and simply fall in line with the expected new conduct and 
behaviour. During this phase, individuals are likely to engage with concepts and new issues superficially, mimicking expected behaviour - their understandings remaining incomplete or partial, causing discomfort and emotional trauma (Land, Meyer and Bailie 2010). In her discussion of 'conceptual threshold crossing', Wisker identifies 'core threshold' concepts that educational research students need to master to be successful in advanced educational research, referring to them as key 'conceptual thresholds' that are 'crucial moments in the research journey, ... when students start to work conceptually, critically and creatively, and so are more able to produce breakthrough thinking' (Wisker 2012, 9). An issue of concern then, especially in the South African context characterised by substantial numbers of novice and inexperienced supervisors, is how and the extent to which research supervisors themselves have acquired the suggested key conceptual thresholds to facilitate such high-level conceptual, critical and creative research endeavours.

In the section that follows, I engage a critical examination of key issues that emerged in the teaching of the Strengthening Postgraduate Supervision course at the six higher education institutions (identified above).

\section{A BRIEF NARRATIVE VIGNETTE}

As described above, the SPS course is an accredited, taught course over three phases with phases 1 and 3 as full contact sessions and phase 2 which was the online session. The course was 'advertised' to South African HEIs and because it was initially funded by Nuffic, there was relatively keen take up. The central research office of each institution (using their internal processes) identified academics they deemed needed this kind of professional development. While a maximum of 25 participants was stipulated some institutions (such as UNIVEN) reported keen interest resulting in classes in excess of 30 participants. Each group comprised participants from a diverse range of disciplines, but predominantly from the hard sciences. Many had limited or no experience of research supervision at Masters or $\mathrm{PhD}$ level, having just worked with small scale research projects of Bachelor of Technology students. More than half of each class group was working towards their own PhD studies. A small number were completing Masters Degrees.

\section{PARALLEL LEARNING OR PARALYSIS?}

From the narrative above, one can discern that the South African research supervision project is complex. At the outset, several participants openly declared their ineptitude both as research student and as supervisor of research. Manathunga and Gozee's caution about the dual 
assumption of the 'always/already’ autonomous student and effective supervisor (Manathunga and Gozee 2007) has particular reference in the South African context. With regard to competence as research student, many participants reflected on their own anxieties about their abilities, explaining how epistemological access was indeed a learning obstacle that continues to present as challenge. Note that this candid declaration (honest revelation) was not peculiar to those who were currently working on their PhD studies, but was also a phenomenon that several $\mathrm{PhD}$ graduated participants also expressed. A very small number of $\mathrm{PhD}$ graduated participants had published out of their $\mathrm{PhD}$ studies and few had engaged with any formal postdoctoral research. While a natural reaction ought to be one of alarm especially since such participants are university academics, the phenomenon of stagnation after graduation is not uncommon in the South African higher education context. The implication here is that such colleagues have not become fully fledged members of their respective academic communities. One might well argue that it is the responsibility of the supervisor to induct the novice researcher into active participation in the academic community of practice (Wenger 1999), in which meaning making, engaging the practices of the community, scholarly identity formation and participation in community of practice such as peer review of scholarly work for example. This is an area worthy of investigation as it is likely to reveal some telling 'truths' about the quality and standard of PhD degrees that academics in South African HEIs hold, including truths about the significance of particular theoretical (and methodological) approaches, research foci as well as vacuous space after doctoral graduation euphoria.

In analyzing the complexity at play in this kind of scenario, the warning sounded by Waghid (2015) and Teferra (2015) about the fragility of the $\mathrm{PhD}$ and the danger of compromising quality is indeed a reality. That quality has been compromised in many instances, is an admission HEIs have to come to terms with, as such recognition and acknowledgement can be sobering and may have the effect of arresting the onward surge and fast tracking of $\mathrm{PhD}$ for all (academics). While there appears to be strong political will to fast track academics, especially colleagues from previously disadvantaged groups, the perils of 'fast tracking' seldom receive due consideration from senior managers and human resource departments of South African higher education institutions eager to demonstrate politically correct employment equity profiles. There is little contention then, that fast tracked $\mathrm{PhDs}$ with their emphasis on thesis completion (product) may well be at the expense of deep, rich, independent high-level conceptual development. What then does this mean for research supervisors who may have had this kind of experience or are currently working on completing their own PhDs? As can be expected, such participants expressed much anxiety; a kind of dissonance that comes when they 
are 'marginally situated' in two spaces (Cook-Sather 2006), one of learner (of research) and one of teacher (of research) as they inhabit this liminal space.

To understand how teaching and learning is likely to happen in this liminal space, one has to necessarily peel back the layers of complexity that encompass this encounter. The university academic, (novice supervisor), as PhD student has to acquire a level of mastery/proficiency as dictated to by the 'rules' set by her disciplinary community; to gain access to the tenets and discourse of the discipline. As mentioned earlier, it may be naive to assume that epistemological access is a given, even for colleagues who are already permanent members of the academic staff at higher education institutions in South Africa. If anything, the popularity of coursework masters degrees with mini-dissertations as well as professional masters degrees $(100 \%$ coursework) have conspired against $\mathrm{PhD}$ candidates who have come through these routes. The consequence of this is that such candidates enter $\mathrm{PhD}$ study significantly under-prepared for the caliber of work expected at this level. In the absence of substantive support (such as structured $\mathrm{PhD}$ programmes), $\mathrm{PhD}$ candidates rely almost entirely on their supervisors for necessary scaffolding; namely, enabling mechanisms and processes for epistemological access. This presents as a somewhat bizarre scenario in which under-prepared academics, for whom the learning curve is precariously steep, embark on $\mathrm{PhD}$ study, while simultaneously teaching their own research students what they (the under-prepared academics) are grappling to apprehend. There is a distinct ripple effect; those at the end of the ripple (the unsuspecting research student) is likely to receive a diluted research supervision 'service'. As this this toxic 'synergy' plays itself out, the ramifications of a compounding effect or multiplier effect is set in motion. The outcome translates into poor, sub-standard research proposals/conceptualisations based on sketchy and shaky understandings of the state of existing theory/literature on the phenomena identified for study, methodological ineptitude and fragile argument construction skills; and ultimately, the production of mediocre research reports and 'advanced' research graduates that lack high-level, finessed conceptual ability. The effect is that the proliferation of the acquisition of 'paper' qualifications is likely to have miniscule impact on the overall quality of the country's labour force. Teferra boldly asserts that South Africa is unashamedly 'exporting' this mediocrity to the rest of Africa. The absence of disciplinary depth as it relates to both the phenomenon under study as well as the methodological astuteness is what Jansen $(2011,140)$ refers to as the acquisition of an 'intimate knowledge of the subject', a necessary precondition for authoritative engagement with the significant focal issues. A preoccupation with the need to meet rigid institutional timeframes for defending research proposals too often means that prerequisite knowledge of the subject (theory and foregoing research) is neglected, with 
consequences which are likely to surface in the later stages of the research process. Thus when the defence of a research proposal that is inadequately informed by theoretical and conceptual knowledge of the targeted phenomenon, does nonetheless succeed, it can be argued that the sequel is likely to be one in which the student generates weak data, has difficulty 'seeing' data, and drifts into superficial analysis and theorising.

Competent supervisors of research ought to be at the cutting edge of knowledge in their chosen disciplinary field and should strive to remain there even after the completion of the $\mathrm{PhD}$. A key revelation from my engagement with colleagues undertaking the research supervision courses in the various institutions cited earlier, is that this aspect of their work as academics did not receive due consideration. What might be perceived a basic techniques for staying abreast of new knowledge and developments in one's field, such as being on the 'research alerts' mailing list of the journals, being actively connected with one's subject librarian, regularly reading 'reviews of literature', and to an extent attending (and presenting) at national and international conferences did not appear to be at the centre of the academic project of many participants. There are several reasons for this; the most crippling and that which renders much of the paralysis is the high teaching and administrative responsibilities that are imposed, especially on young staff. The consequence is that such colleagues struggle to develop an authoritative voice and a solid base from which to induct their own advanced research students. This is indeed a striking paradoxical context, a somewhat cynical milieu in which the $\mathrm{PhD}$ candidate university academic, having yet to be accepted by his peers into her aspirational academic community (where peer validation of competence is a valued tradition), has to attempt to 'induct' their own students into what can be a 'vicious' academic space, the boundaries of which are often patrolled by tenacious, unforgiving gatekeepers. This presents as a daunting, precarious liminal space that the $\mathrm{PhD}$ candidate academic has to navigate. The tragedy is that higher education managers seldom have any ‘sophisticated' understanding of this, nor empathy for such individuals, nor any constructive 'humane' plan to support such faculty.

\section{TOWARDS SUPERVISION AS PEDAGOGY - OVERCOMING THE AVERSION TO EDUCATIONAL LITERATURE}

As stated earlier, the supervision capacity development programme (SPS) was a formal accredited higher education academic programme. As such it necessarily demanded independent reading (of prescribed and recommended literature) and responses to multiple learning activities specially designed to help participants achieve the outcomes of the programme. Participants (identified by each institution's central research office) came from a 
wide range of disciplines. It was not unusual to expect that there would be diverse disciplinary perspectives (ontological, epistemological and methodological) to research. As such each cohort presented with several layers of complexity as it related to understanding and achieving the outcomes of the programme.

One of the key challenges was to 'convince' participants to engage with the prescribed literature. Two issues were at play here. Firstly, because continuing professional development 'programmes'/'interventions' for academic staff have historically been short day-long or twoday workshops, often with loosely framed outcomes and the absence of tangible 'products' to be produced by participants, the first challenge for me as facilitator (and for other facilitators) was to rupture this approach to thinking about this programme 'intervention'. What was evident was that several participants had a somewhat casual attitude to the programme. It was thus necessary to explain the full extent of all three phases of the programme as well as emphasizing that it was a 'taught' programme with assessments. While the assessments were important, we were mindful of not having this aspect unduly influencing teaching and learning in the programme. The 'extended' duration of the course (three months) was intended to enhance the principle of learning as 'process' with the view to creating conditions for 'deep learning'. As declared above, the impact of this kind of intervention was likely to be marginal in the short term; it was only once the 'new' thinking about supervision had been applied and had time to 'bed' that any significant outcomes of this intervention could be discerned.

Secondly, and arguably the more challenging aspect of facilitating a programme of this nature was having to manage the participants' aversion to engaging substantively with educational research literature, in this instance, research literature and theory as it relates to supervision as pedagogy. Of note was that this aversion was a feature not just peculiar to colleagues from the hard sciences; even participants in the social sciences demonstrated a distinct reluctance to engage with theory as it related to postgraduate supervision. Participants in the natural sciences were particularly 'suspicious' and even snobbishly skeptical of 'soft' science educational research as it related to the study of research supervision. It became evident that the task of deconstructing canonical approaches (largely characterized by apprenticeship models of supervision) would prove to be to be particularly challenging. What was also evident was that much of the supervision enterprise at these institutions proceeded from lay understandings of educational theory with very limited engagement with theories of teaching and learning as they may apply to research supervision as pedagogy. Liberal approaches to research supervision appeared to be firmly entrenched in the culture and practices of the academic departments from which these participants came. As can be expected, this 
apprenticeship of observation (Lortie 1975) was likely to have cultivated particular constructions of what these participants understood to be their responsibilities as supervisors and what they believed was not!

The first theme of the programme, which focused on understanding power relations in supervision and the need to create inclusionary and participatory learning environments was met with much skepticism. Social justice concerns as they related to challenges that might manifest with issues of race, class, language, xenophobia and other forms of overt and subtle othering, appeared to have little currency in the eyes of several participants, many arguing that research supervision was about thesis completion in regulation time. As such, dealing with socalled 'Dr Phil' issues were outside of the core brief of the supervisor. The 'demeaning effects of discriminatory relations in supervisory encounters and the management of unequal power relations' (a sub-theme of the programme) was an aspect that participants regarded as peripheral to the research supervision enterprise. Contemporary post-liberal literature however argues that this needs to be a core element of a research supervisor's repertoire of competences. In a South African context characterized by a long history of prejudicial practices, an argument for this kind of competence is not without substance. This presents as a particular tension where the young $\mathrm{PhD}$ candidate academic learns the research trade in research communities 'stuck' in traditional worldviews of the research supervision enterprise, an issue that manifests in somewhat narrow understandings of their responsibilities as supervisors, a discussion of which ensues.

\section{WHOSE JOB IS TO 'TEACH' RESEARCH?}

As noted above, Manathunga and Gozee's caution about the dual assumption of the 'always/already’ autonomous student and effective supervisor (Manathunga and Gozee 2007) has distinct reference. Many participants in the programme (across all the institutions in the sample) were typically young, novice researchers who were thrust into postgraduate research supervision without due assessment of their existing competences and capacities to undertake this high-level function. They often complained that they were allocated the 'weakest' students, which the established and experienced academics had rejected (declined to supervise). That students in South Africa enter Masters and PhD research study with gaps in high-level conceptual abilities required for success in these programmes is indeed a moot point. It follows then that scaffold learning for such students it might well be a pedagogic necessity. Of concern tough is that participants in the SPS programme did not conceive this as 'part their job', arguing that research students ought to have arrive with the necessary competences in place or, if it was 
not, then such students had to seek out (on their own) ways to develop such competences. The notion of 'teaching' research skills, from conceptualizing a research study, constructing a literature review, developing methodological expertise, mastering data analysis skills and theorization were deemed facets of the research learning enterprise that ought to be the responsibility of the student. In other words, the onus was on the research student to acquire this repertoire of competences. A practice of only accepting full, close to final drafts (of chapters) appeared to be the norm. Nuanced understandings of research as pedagogy and 'continuous assessment' of student work as formative, appeared to be foreign in many instances. The inference that can be derived from this may well be that this was the experience that the $\mathrm{PhD}$ candidate academic was living and/or that that they did not possess the necessary pedagogical skills to assess their own students' needs nor the competence to respond adequately to these. To its credit, the SPS programme had a particular focus on developing student writing using formative feedback. The extent to which this was applied by the participants is an area of follow-up research that the programme managers could well take up.

\section{DISSONANCE AS A NECESSARY PART OF LEARNING}

In a seminal piece entitled 'The Theory of Cognitive Dissonance', Leon Festinger described the construct 'dissonance' as a state of 'psychological discomfort' that arises out of 'the existence of non-fitting relations among cognitions' (Festinger 1957, 2). Cognitions, he explained refer to beliefs about oneself, one's behaviour or the environment. He argued that dissonance has motivational potential as it is likely to propel the individual towards actively striving to reduce dissonance. This is an important insight as it suggests that individuals seldom construct themselves as ‘trapped' or locked 'permanently' into particular situations. If anything, they hone their skills to better manage themselves in such constraining contexts. In applying this to the context of the $\mathrm{PhD}$ candidate academic, it can be discerned that, as she engages the supervision activity because she is compelled to and is not 'ready', she does so knowing that it may have negative consequences for her students, given the gaps in her own knowledge of both research and supervision. So while there is a naïve belief by her line managers that the effect on students is not as serious as many people make it out to be, she may not be convinced by this. She is also acutely aware that not taking up supervision may have other negative repercussions for her. One can argue that this dissonance is likely to trigger learning and growth as the $\mathrm{PhD}$ candidate attempts to reduce dissonance.

Thus, in navigating the perils (and opportunities) of the academic terrain, it is imperative that the novice $\mathrm{PhD}$ candidate academic understands and accepts that dissonance is a necessary 
pre-condition for learning, and that dissonance leads to growth. It follows then, that due consideration be given to creating this level of meta-awareness, in ways that will enable the $\mathrm{PhD}$ candidate academic to manage the discomfort/dissonance, and to internalise it as a necessary ‘ambiguous’ condition for and of learning.

Another layer of dissonance that was experienced derived from the implicit assumptions of the SPS programme itself. These are worth troubling as they illuminate inconsistencies that manifest with continuing professional development initiatives/programmes based on the 'outside in’ model. Such programmes, usually conceptualised at a broad, generic, universal level, are likely to be highly structured and rigid, and are often facilitated by external agents. As such, these conceptualisations cannot capture the nuances and peculiarities of individual sites of delivery. The materials and content (in the current programme) for instance are designed for $\mathrm{PhD}$ academics who are beginning their $\mathrm{PhD}$ supervision careers. The reality as described in the vignette above, is that many colleagues who signed up for the programme were working on their own PhD studies and could not be PhD supervisors, but were supervising at a masters or honours level, creating a disjuncture between the course outcomes and the expectations of the participants.

It also became clear that the course was designed by educational and social science researchers/academics whose bias for qualitative, interpretive social science research infused the entire programme. The pool of programme facilitators were also drawn from this arena. This presented as a particular challenge for participants whose academic worlds were different from the ontological and epistemological orientation of the programme and the facilitators. It was difficult for me for example, to engage 'intelligently' with the work of participants whose research was located in the hard sciences. So while there is an argument for understanding and responding to the dissonance of the participants, an argument can also be made that that even the facilitators of the programme had experienced some level of dissonance.

\section{CONCLUDING COMMENTS}

Given that under 35 per cent of all academics in SA hold a $\mathrm{PhD}$ qualification, the liminal becomes a crucial nexus that will influence the future strength of the SA higher education sector. How colleagues survive and negotiate liminality, a state of being marginally situated between two spaces, is indeed a cause for serious concern and worthy of systematic investigation with a view to arresting the slide in the academic endeavor. Of importance is the recognition and acknowledgement that dissonance is a necessary condition for and of learning. There is thus a need to develop a meta-cognitive awareness of this phenomenon by $\mathrm{PhD}$ 
candidate academics. There is also much to learn about the shortcomings of outside-in professional development initiatives, especially those whose ontological and epistemological assumptions do not cohere with the paradigmatic orientation of the audience.

While the foregoing exposition is not meant to 'pathologise' the plight of the young academic or the research supervision context in South Africa, it draws attention to some of the symptomatic issues at play in the higher education space. It signals the peculiar concerns that demand our immediate consideration, especially since the research supervision enterprise, is what will nourish the breeding ground for the new generation of intelligentsia. If left unchecked, the system may well default to the abyss that Yusef Waghid and Damtew Teferra rightfully caution us about.

\section{REFERENCES}

Adkins, B. 2007. PhD pedagogy and the changing knowledge landscapes of universities. Higher Education Research and Development 28(2): 165-177.

ASSAF. 2010. The PhD Study. Edited by Academy of Science of South Africa. Pretoria.

Burford, J. 2014. Doctoral writing as affective practice: Keep calm and carry on. In Pushing boundaries in postgraduate supervision, ed. E. M. Bitzer, R. M. Albertyn, L. Frick, B. Grant and F. Kelly, 69-84. Stellenbosch: SUN Press.

Clegg, S. 2014. Knowledge questions and doctoral education. In Pushing boundaries in postgraduate supervision, ed. E. M. Bitzer, R. M. Albertyn, L. Frick, B. Grant and F. Kelly, 11-24. Stellenbosch: SUN Press.

Cook-Sather, A. 2006. Newly betwixt and between: Revisiting liminality in learning to teach. Anthropology and Education Quarterly 37(2): 110-127.

Festinger, L. 1957. The theory of cognitive dissonance. California: Stanford University Press.

Grant, C. 2014. Pushing the boundaries of postgrauate supervision: Theorising research learning in community. In Pushing boundaries in postgraduate supervision, ed. E. M. Bitzer, R. M. Albertyn, L. Frick, B. Grant and F. Kelly, 109-122. Stellenbosch: SUN Press.

Jansen, J. 2011. The quality of doctoral education in South Africa. Perspectives in Education 29(3): 139-146.

Land, R., J. H. F. Meyer and C. Bailie. (Ed.) 2010. Threshold concepts and transformational learning. Rotterdam: Sense Publishers.

Lortie, D. C. 1975. Schoolteacher: A sociological study. Chicago: University of Chicago Press.

Manathunga, C. 2009. Supervision as a contested space: A response. Teaching in Higher Education 14(3): 341-345.

Manathunga, C. and J. Gozee. 2007. Challenging the dual assumption of the 'alway/already' autonomous student and effective supervisor. Teaching in Higher Education 12(3): 309-322.

National Planning Commission. 2012. National Development Plan 2030. Pretoria: Office of the Presidency. http://www.npconline.co.za

Szakolczai, A. 2009. Liminality and experience: Structuring transitory situations and transformative events. International Political Anthropology 2(1): 141-172.

Teferra, D. 2015. Manufacturing and exporting excellence and 'mediocrity': Doctoral education in South Africa. South African Journal of Higher Education 29(5): 8-19.

Thaver, B. and L. Holtman. 2015. A response to Yusuf Waghid's leading article. South African Journal 
of Higher Education 29(5): 20-28.

Turner, V. 1974. Dramas, Fields and Metaphors: Symbolic Action in Human Society. New York: Cornell University Press.

Waghid, Y. 2005. Education, imagination and forgiveness. Journal of Education 37: 225-241.

Waghid, Y. 2015. Are doctoral studies in South African higher education being put at risk? South African Journal of Higher Education 29(5): 1-19.

Wenger, E. 1999. Communities of practice: Learning, meaning and identity. New York: Cambridge University Press.

Wisker, G. 2012. The good supervisor: Supervising postgraduate and undergraduate research for doctoral theses and dissertations. London: Palgrave macMillan.

Wisker, G., G. Robinson and M. Schacham. 2007. Postgraduate research success: Communities of practice involving cohorts, gaurdian supervisors and online communities. Innovations in Education and Teaching International 44(3): 301-320. 